\title{
Occupant Risk Evaluation Based on Frontal Collision of Bus
}

\author{
Zhang Guosheng \\ Research Institute of Highway Ministry of Transport \\ Beijing, China \\ e-mail: gs.zhang@ rioh.cn \\ Wang Yang \\ Oilfield Road Management Company of Daqing \\ Petroleum Administrative Bureau \\ Daqing, China \\ e-mail: 702133622 @qq.com
}

\author{
Li Qiang \\ Research Institute of Highway Ministry of Transport \\ Beijing, China \\ e-mail: qiang.li@ rioh.cn \\ Li Zicheng \\ Research Institute of Highway Ministry of Transport \\ Beijing, China \\ e-mail:zc.li@ rioh.cn
}

\begin{abstract}
This article took the type of 6900 passenger car as an object reference, referred protection of the occupants in the event of a frontal collision (ECE R94) and protection of the occupants of the cab of commercial vehicles (ECE R29). Through the analysis of the initial energy when the bus was collision and took advantage of the software LS-DYNA to analyze the impact tests of pendulum and fixed barrier wall, respectively. By calculated the displacement and acceleration of the framework, it determined using the frontal collision evaluation was reasonable. On this basis, it selected the collision speed-30 $\mathrm{km} / \mathrm{h}$ to conduct the frontal passenger crash test in real vehicle that of fixed barrier wall. And then, it analyzed the impact of two-point and three-point seat belts harness on the bus occupant safety. The results showed that: the three-point seat belt protection was better than two-point seat belts, so the three-point seat belts arrangement should be installed on buses, possibly.
\end{abstract}

Keywords- Crashworthiness; frontal collision; ECE R94; ECE R29

\section{INTRODUCTION}

According to the accident statistics for buses, accidents involving frontal collision constitute an important percentage among all bus accidents. In this type of accidents, front body of the bus structure gets severely damaged and this puts the driver and crew in great injury risk. And most of the frontal collision accidents result in death of the bus driver. Because of this, the safety of both the bus driver and the crew should be ensured in the case of frontal collision accidents. Providing the driver's safety is crucial since the driver is the key person for keeping the control of the bus in the event of an accident so that the safety of the passengers will be ensured [1].

There is no complete test methods and evaluation system, also no mandatory regulatory requirements in currently systems. This article takes a type of 6900 bus as study object, using the FEA procedure LS-DYNA to investigate the test techniques and the evaluation methods in the front structure of bus. On this basis, with the real vehicle tests to analysis of the bus occupant safety on the two-point seat belts and three-point seat belts, and provide technical support for the development of relevant standards.

\section{BASIC THEORY}

Even though the most of the passive safety standards are related to the safety of the passengers, some international regulations exist for the driver's safety for heavy vehicles. The European regulation ECE-R29 is arranged to provide the safety of the truck cabin and the driver. This regulation involves a frontal crash pendulum test in which a plate with a specified mass strikes the cabin of the vehicle. A regulation specifically arranged for the safety of bus in the case of frontal crashes does not exist, but some proposals similar to ECE-R29 are being discussed in Working Party on Passive Safety (GRSP) in UNECE.

The pendulum is simulated as rigid elements, without considering the deformation of the pendulum during the impact. In view of no unifed regulations in impact energy for bus, a reasonable impact velocity must be established in terms of different commercial vehicles. Volvo has done the experiment with impact energy twice as the specifed value based on ECE R29. The 96th International Conference of WP29/GRSG [2] has been proposed $80 \mathrm{~kJ}$ energy as impact energy of pendulum. Federal Motor Vehicle Safety Standard proposed some requirements on Front crash about the school bus. In 2009, the Chinese bus academic forum annual meeting proposed to draft the national standards "Front crash of bus' requirements" for the first time. There are two test methods: 1.The front pendulum tests; 2 .The front barrier crash tests [3][4][5].

When the bus has a front impact on the fixed rigid barrier, in accordance with the $7000 \mathrm{Kg}$ quality to calculate, we can know that when the impact velocity is $30 \mathrm{Km} / \mathrm{h}$, the initial impact energy is about $243.1 \mathrm{KJ}$, and the impact energy is approximately 5 times of the pendulum impact energy $(44.1 \mathrm{KJ})$ or 8 times $(29.4 \mathrm{KJ})$. 


\section{ANALYSIS OF IMPACT ENERGY}

\section{A. Finite Element Model}

This article takes the type of 6900 passenger car as an object reference, the bus body consists of front body, front chassis, right and left side walls, roof, steering systems. The overall bus finite element model consists of 467,999 nodes and 467,248 shell elements.

TABLE I. BASIC PARAMETERS

\begin{tabular}{|c|c|c|c|}
\hline Item & Parameters & Item & Parameters \\
\hline Kerb mass & $8500 \mathrm{~kg}$ & $\begin{array}{c}\text { front / rear } \\
\text { overhang }\end{array}$ & $1905 / 2790 \mathrm{~mm}$ \\
\hline Wheelbase & $4300 \mathrm{~mm}$ & Axle load & $3800 / 8190 \mathrm{~kg}$ \\
\hline $\begin{array}{c}\text { number of } \\
\text { axles }\end{array}$ & 2 & $1^{*} \mathrm{w}^{*} \mathrm{~h}$ & $\begin{array}{c}8995 / 2480 / 3335 \\
\mathrm{~mm}\end{array}$ \\
\hline
\end{tabular}

\section{B. The Pendulum Test}

The finite element analysis of this study was conducted by using explicit nonlinear finite element code LS-DYNA. The bus structure was crashed with a pendulum having a mass of $1500 \mathrm{~kg}$ as described in the ECE R29 regulation.

The regulation proposes an impacter plate which is made up of steel material and having a mass of $1500 \pm 250$ $\mathrm{kg}$. This impacter has to be a rectangle with a width of $2500 \mathrm{~mm}$ and a height of $800 \mathrm{~mm}[6][7]$. According to the regulation the impact energy should be at least $45 \mathrm{~kJ}$ for the vehicles exceeding $7000 \mathrm{~kg}$ of mass. Under these conditions the driver's survival space should be checked after the test. For this purpose, a manikin should be used which is described in the regulation.

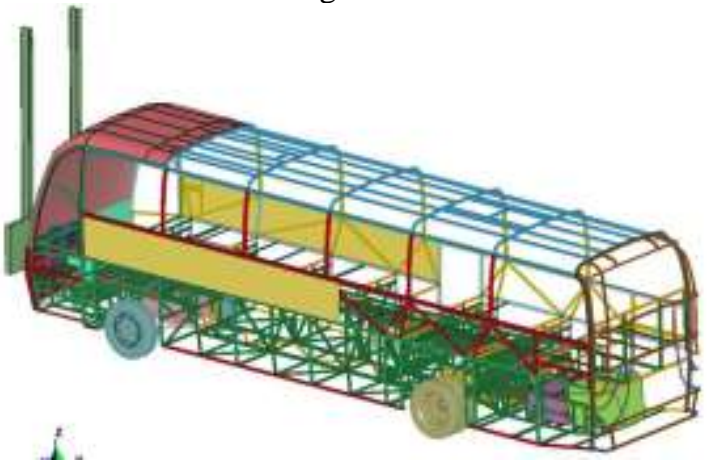

Figure 1. Pendulum and Bus

According to ECE R-29 regulation the desired kinetic energy of the pendulum is $45 \mathrm{~kJ}$. This energy is given to the system as a kinetic energy. The desired angular velocity of the pendulum can be calculated by Equation 1, in order to obtain the required kinetic energy. The mass moment inertia of the pendulum plate about $y$-axis can be calculated by Equation 2 .

$$
\begin{aligned}
E & =\frac{1}{2} I_{y y} \omega_{y}^{2} \\
I_{y y} & =I_{y_{c} y_{c}}+m L^{2}
\end{aligned}
$$

The angular velocity of the pendulum was found to be $\omega=2.2131 \mathrm{rad} / \mathrm{s}$.

\section{Frontal Collision of Bus}

If want the energy of the $7000 \mathrm{Kg}$ bus hits the rigid barrier equals to the pendulum impact energy (29.4 KJ and $45 \mathrm{KJ})$, the corresponding bus impact velocity were $10.4 \mathrm{Km} / \mathrm{h}$ and $12.8 \mathrm{~km} / \mathrm{h}$ by Equation 3 .

$$
E=\frac{1}{2} m v^{2}
$$

If want the pendulum impact energy reach to the initial impact energy $(243 \mathrm{KJ})$ of the $7000 \mathrm{Kg}$ bus hits the rigid barrier with the speed of $30 \mathrm{~km} / \mathrm{h}$, supposing the arm length unchanged, is still $3500 \mathrm{~mm}$, then the pendulum mass should be increased to $7000 \mathrm{Kg}$ ( the existing mass is $1500 \mathrm{Kg}$ ) or heavier. Therefore, the initial impact energy of the existing two kinds of test methods has a greater difference, as well as the caused deformation, and two test modes are difficulty to equate.

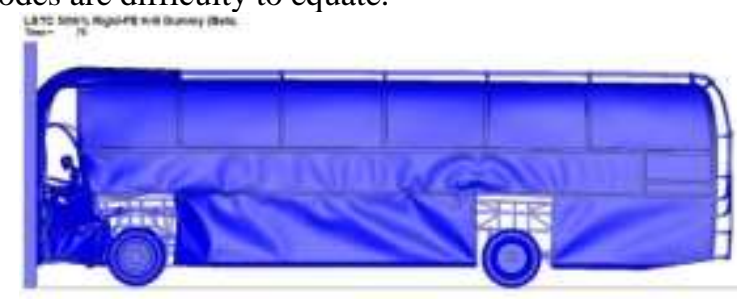

Figure 2. Fixed barrier wall and bus

In this paper, we used the initial collisions speed of 30 $\mathrm{km} / \mathrm{h}, 35 \mathrm{~km} / \mathrm{h}$ and $40 \mathrm{~km} / \mathrm{h}$ to analyze the initial collision energy. The front door frame longitudinal deformation is shown in tab.2. By calculated the displacement and acceleration of the framework, it determined using the head-on collision evaluation was reasonable.

TABLE II. FRONT DOOR FRAME LONGITUDINAL DEFORMATION

\begin{tabular}{|c|c|c|c|}
\hline Test speed & $\begin{array}{c}\text { The upper } \\
\text { sampling point }\end{array}$ & $\begin{array}{c}\text { The central } \\
\text { sampling point }\end{array}$ & $\begin{array}{c}\text { The lower } \\
\text { sampling point }\end{array}$ \\
\hline $30 \mathrm{~km} / \mathrm{h}$ & $18 \mathrm{~mm}$ & $291 \mathrm{~mm}$ & $140 \mathrm{~mm}$ \\
\hline $35 \mathrm{~km} / \mathrm{h}$ & $35 \mathrm{~mm}$ & $378 \mathrm{~mm}$ & $210 \mathrm{~mm}$ \\
\hline $40 \mathrm{~km} / \mathrm{h}$ & $54 \mathrm{~mm}$ & $557 \mathrm{~mm}$ & $355 \mathrm{~mm}$ \\
\hline
\end{tabular}

\section{REAL VEHICLE TEST AND ANALYSIS RESULTS}

The vehicle's requires suspensions, tires and steering systems should be in a normal working condition. The fixed counterweight should be evenly distributed in the interior of the vehicle[8]. According to the pre-developed real vehicle crash test program requirements, a GB foam dummy which's size is same as the Hybrid III 50th percentile adult male test dummies is placed in the drive's position, and a HybridIII 50th percentile adult male test dummy is placed in the seat which is on the left of the first row after the driver's seat and near the channel, and than a Hybrid III 50th percentile adult female test dummy is placed in the seat which is on the right of the first row after the driver's seat and near the window, and in the head, the knee should be coated with color, as shown in Figure 3. 




(a) Test bus

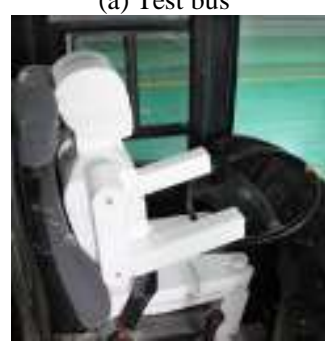

(b) Foam dummy

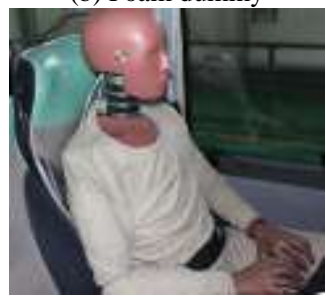

(c) Male test dummy

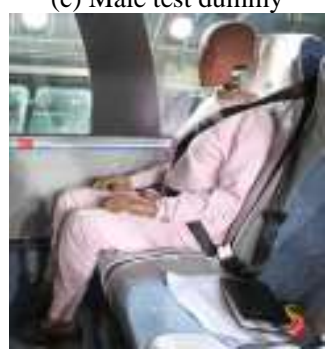

(d) Female dummy

Figure 3. Data Collection Instruments layout

\section{A. Deformation Analysis of Collision Area}

During the collision, that the bus frame is all-bearing truss structure and the impact energy is almost absorbed by the front deformation results in a great deformation of the bus front and a about 430mm crumple distance; the collision makes the dashboard and steering wheel move back and seriously squeeze the driver; after the collision, the front windshield is broken but not deciduous and the other windows are in good condition; the doors do not pen themselves during the test and the passenger door and driver side door get stuck after the test and can not be used; the fuel system does not have fuel leakage after the test. Deformation of the bus front structure is shown in Figure 4

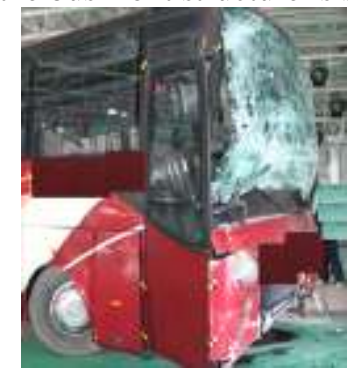

(a) right front $45^{\circ}$

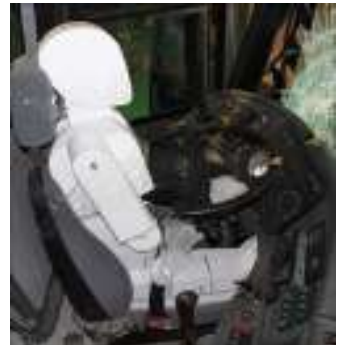

(b) driving area

Figure 4. Deformation of the Bus Front Structure

\section{B. Injury Criterions and Dummy Appraisement}

The performance of all the test dummies should meet the following requirements: the head performance indicators (HIC36) should be less than or equal to 1000; the thorax performance indicators (ThPC) should be less than or equal to $75 \mathrm{~mm}$; the femur performance indicators (FPC) should be less than or equal to $10 \mathrm{KN}$ [9][10]. The criterion of HIC is worked out by CMVDR 294 and occidental rule based on Equation 4 [11][12].

$$
H I C=\left\{\left[\frac{1}{t_{2}-t_{1}} \int_{t_{1}}^{t_{2}} a(t) d t\right]^{2.5}\left(t_{2}-t_{1}\right)\right\}<1000
$$

Where, $a(t)$ is the resultant linear acceleration time history (g's) of the center of gravity of the head, and $t_{1}$ and $t_{2}$ the interval between every $36 \mathrm{~ms}$ of the crash process which produced the maximal HIC. $\mathrm{C} 3 \mathrm{~ms}$ is the $3 \mathrm{~ms}$ criterion of the chest acceleration.

From the tab.3, we can see that the chest compression of the test dummy 1 is $37.42 \mathrm{~mm}$, far less than $75 \mathrm{~mm}$ which is provided in the standards and regulations, will not hurt the dummy' chest; The chest compression of the test dummy 2 has not been colleted. The left and right leg axial force of the two test dummies is 0.7 to $1.41 \mathrm{kN}$, less than $10 \mathrm{kN}$ which is the thigh bone axial tolerance limit.

TABLE III. THE IMPACT PARAMETERS OF THE TEST DUMMY

\begin{tabular}{|c|c|c|}
\hline Test Project & Maximum Value & Time(s) \\
\hline Passenger 1-Chest-Distance & $37.42 \mathrm{~mm}$ & 0.2264 \\
\hline Passenger 1-Left-Leg-Force & $0.703 \mathrm{KN}$ & 0.0789 \\
\hline Passenger 1-Right-Leg-Force & $1.277 \mathrm{KN}$ & 0.1481 \\
\hline Passenger 1-Neck- FX & $2.046 \mathrm{KN}$ & 0.1488 \\
\hline Passenger 1-Neck- MY & $79.85 \mathrm{Nm}$ & 0.1507 \\
\hline Passenger 1-Neck- FZ & $0.887 \mathrm{KN}$ & 0.1463 \\
\hline Passenger 2-Left-Leg-Force & $1.211 \mathrm{KN}$ & 0.0124 \\
\hline Passenger 2-Right-Leg-Force & $1.411 \mathrm{KN}$ & 0.1322 \\
\hline
\end{tabular}

\section{Safety Belt Protection Effect}

From the tab.4, we can see that the test dummy 1 wore a two-point belt, and the upper limb generated whiplash action made head $\mathrm{X}$-acceleration is too large, and the maximum reached $250 \mathrm{~g}$ made the value of HIC36 is 1586 which is beyond the tolerance limits of the human body. We know the test dummy 1 will die because of head injuries; the test dummy 1 wore a three-point belt which can better restrain the dummy, so each of the head acceleration are relatively small. 
TABLE IV. THE IMPaCt Parameters of THE Test DUMmy

\begin{tabular}{|c|c|c|c|c|c|}
\hline \multicolumn{2}{|c|}{ Passenger 1-Head (two-point belt) } & \multicolumn{3}{|c|}{ Passenger 2-Head (three-point belt) } \\
\hline Test Project & $\begin{array}{c}\text { Maximum } \\
\text { Measured } \\
\text { Value }\end{array}$ & Time(s) & Test Project & $\begin{array}{c}\text { Maximum } \\
\text { Measured } \\
\text { Value }\end{array}$ & Time(s) \\
\hline $\begin{array}{c}\text { X- } \\
\text { Acceleration }\end{array}$ & $250.2 \mathrm{~g}$ & 0.1480 & $\begin{array}{c}\text { X- } \\
\text { Acceleration }\end{array}$ & $23.9 \mathrm{~g}$ & 0.1277 \\
\hline $\begin{array}{c}\text { Y- } \\
\text { Acceleration }\end{array}$ & $69 \mathrm{~g}$ & 0.148 & $\begin{array}{c}\text { Y- } \\
\text { Acceleration }\end{array}$ & $5.635 \mathrm{~g}$ & 0.1434 \\
\hline $\begin{array}{c}\text { Z- } \\
\text { Acceleration }\end{array}$ & $30.03 \mathrm{~g}$ & 0.1482 & $\begin{array}{c}\text { Z- } \\
\text { Acceleration }\end{array}$ & $15.66 \mathrm{~g}$ & 0.0839 \\
\hline HIC & 1586 & $/$ & HIC & 76 & $/$ \\
\hline
\end{tabular}

According to Equation 4, safety belt protection effect is shown in Fig.5 and Fig.6. By comparing the analysis of the test results, three-point safety belt protection was better than two-point seat belts, so the three-point seat belts arrangement should be installed on buses, possibly.

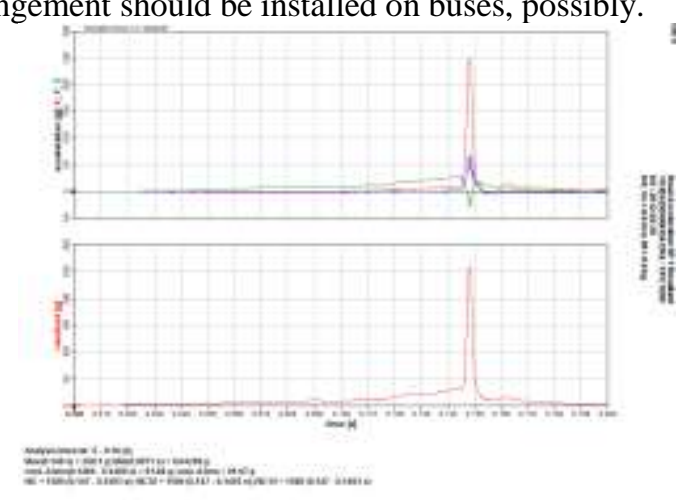

Figure 5. dummy wore two-point belt

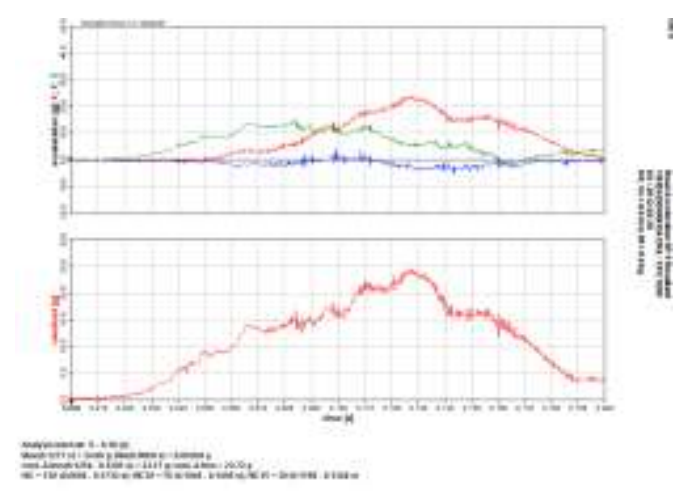

Figure 6. dummy wore three-point belt

\section{CONCLUSIONS}

(1) Referring to the regulations of protection of the occupants in the event of a frontal collision (ECE R94) and protection of the occupants of the cab of commercial vehicles (ECE R29). Revolved the two ways of the pendulum hammer and the fixed barrier wall, used the initial collisions speed of $30 \mathrm{~km} / \mathrm{h}, 35 \mathrm{~km} / \mathrm{h}$ and $40 \mathrm{~km} / \mathrm{h}$ to analyze the initial collision energy, and determined the speed of $30 \mathrm{~km} / \mathrm{h}$ bump under the fixed barrier wall to evaluate the front passenger structural safety.

(2) On this basis, it designed the test program of the front passenger crash, including the test site, the orientation of the barrier, the vehicle conditions, the dummies, the vehicle's driving system, the test speed and the location and other requirements of the vehicle's dates measurement. It conducted the tests in the real vehicle, repeatedly. By comparing the analysis of the test results, three-point safety belt protection was better than two-point seat belts, so the three-point seat belts arrangement should be installed on buses, possibly.

\section{REFERENCES}

[1] KO Hee-Young, SHIN Kwang-Bok, JEON Kwang-Woo. A study on the crashworthiness and rollover characteristics of low-floor bus made of sandwich composites [J]. J of Mechanical Sci and Tech, 2009, pp. 86-93.

[2] LI Suxia, LEI Zhengbao, FUAijun. Frontal collision analysis of a minibus with CST [J]. J Transport Sci and Eng, 2010, pp. 30-35.

[3] LI Sanhong, GUO Konghui, Zhao Youping, et al. Frontal pendulum impact test and computer simulation of commercial vehicles [J]. Chinese J of Mech Eng, 2005, pp. 23-30.

[4] ECE/R94, Uniform provisions concerning the approval of vehicles with regard to the protection of the occupants in the event of a frontal collision[S].Geneva: United Nations, 2008.

[5] protection of the occupants of the cab of commercial vehicles (ECE R29) [S].

[6] WANG Xin, YAN Changzheng. The discussion of bus on frontal impact standard [C]// 2010 China Int Conf of Automotive Safety Technology, SAE-China, Chongqing, 2010.

[7] WANG Xiao, JIAN Xiaochun. Improved Structure Design for Bus Front Framework Based on the Pendulum Test[J]. Automotive Safety and Energy, 2011, pp. 308-311.

[8] GB11551-2003, The protection of the occupants in the event of a frontal collision for motor vehicle[S]. Beijing: China Standards Publishing House, 2007.

[9] Ma Chunsheng, Huang Shilin, Zhang Jinhuan. Research On Injury Criterions Prescribed In

[10] Automotive Frontal Crash Regulations [J]. Journal of Highway and Transportation Research and Development. 2004, 2 pp. 94-97.

[11] Priya Prasd, Jamal E.Belwafa. Vehicle Crashworthiness and Occupant Protection [A].American

[12] Iron and Steel Institute 2000 Town Center Southfield, Michigan 48075,2004, pp.1-10 